\title{
COVID-19-associated euglycemic diabetic ketoacidosis in a patient with type 2 diabetes on SGLT2 inhibitor: a case report
}

\author{
Daniel Valente Batista ${ }^{1,3} \cdot$ Carla Antoniana Ferreira de Almeida Vieira ${ }^{2} \cdot$ Thomaz Alexandre Costa $^{2}$ (D) \\ Eduardo Gomes Lima ${ }^{3}$
}

Received: 17 August 2020 / Accepted: 15 October 2020 / Published online: 28 October 2020

(c) The Japan Diabetes Society 2020

\begin{abstract}
Type 2 diabetes mellitus (DM) patients are at high risk for the development of severe COVID-19. Euglycemic diabetic ketoacidosis (eu-DKA) is a rare life-threatening complication associated with the use of SGLT2 inhibitor that may be unnoticed, particularly in a pandemic setting, due to the absence of significant hyperglycemia, delaying its treatment. In this report, we describe a case of a 56-year-old patient who presented an elevated anion gap metabolic acidosis during a SARS-CoV-2 infection and was diagnosed with SGLT2-associated euglycemic diabetic ketoacidosis. COVID-19 may increase patients' insulin demand, present gastrointestinal symptoms, and increase the production of ketone bodies. This situation can be worsened in susceptible diabetic patients on SLGT2 inhibitors, due to the persistent glycosuria, which can cause volume depletion. Recently some authors recommended that insulin-deficient patients or those using SGLT2 inhibitors should monitor for ketosis using available home testing kits in case of infections and should discontinue the medication in case of COVID-19. Given the increased use of this drug class in the management of type 2 DM patients due to its reduction of cardiovascular risk, we set out to emphasize the importance for the medical community to consider the possibility of eu-DKA on SARSCoV-2-infected patients using SLGT2 inhibitors, so physicians can provide these patients with appropriate therapy promptly.
\end{abstract}

Keywords Coronavirus disease 2019 (COVID-19) · Type 2 diabetes · Euglycemic diabetic ketoacidosis · SGLT2 inhibitor

\section{Introduction}

Patients with type 2 diabetes mellitus (T2DM) seem to have increased risk for more severe SARS-CoV-2 infections and higher mortality rate, regardless of age, especially when there is poorly controlled blood glucose [1-3].

Diabetic ketoacidosis (DKA) is an acute and potentially lethal complication of both type 1 diabetes mellitus and T2DM, defined by the triad of hyperglycemia (>250 mg/ $\mathrm{dL}$ ), high anion gap metabolic acidosis, and increased plasma ketones [4]. However, DKA can occur without

Thomaz Alexandre Costa

thomazacosta@gmail.com

1 Hospital Alemão Oswaldo Cruz, Intensive Care Unit, São Paulo, Brazil

2 Clinical Pharmacology Unit, Drug Research and Development Center (NPDM), Federal University of Ceará (UFC), Coronel Nunes de Melo \#1000, Fortaleza, CE 60430-275, Brazil

3 University of Sao Paulo Heart Institute, São Paulo, Brazil marked hyperglycemia, often $<200 \mathrm{mg} / \mathrm{dL}$, which is called euglycemic DKA (eu-DKA) [5].

In May 2015, the Food and Drug Administration (FDA) warned that treatment with sodium-glucose cotransporter-2 (SGLT2) inhibitors may increase the risk of ketoacidosis [6]. Several publications reporting the association between these drugs and eu-DKA have been published since then $[5,7,8]$. The frequency of reported DKA events related to SGLT2 inhibitor treatment in T2DM patients is less than $0.1 \%$ [9]. Eu-DKA is a life-threatening emergency in those patients, presumably poorly recognized and underreported due to the absence of significant hyperglycemia. Although some mechanisms for this adverse effect have been proposed [10], further investigation is needed to understand its causes.

We describe a case of eu-DKA associated with COVID19 in an individual with T2DM in the setting of SGLT2 inhibitor therapy. As COVID-19 pandemic has grown a great public health issue, this report is particularly relevant considering the role of diabetes in the severity of SARSCoV-2 infections and the possibility of delayed diagnosis of eu-DKA and its adverse metabolic consequences [2, 3, 5]. 


\section{Case report}

A 56-year-old man with a history of systemic arterial hypertension and T2DM presented to an Emergency Department (ED), brought by his relatives, with myalgia, fever, and cough. Symptoms began 5 days prior admission to the ED, situation in which the patient was in poor general condition, requiring support to walk. The patient denied history of alcohol or illicit drug use, diarrhea, vomiting, bleeding, or previous surgeries.

At that time, the patient was on losartan $50 \mathrm{mg}$ once a day, metformin $850 \mathrm{mg}$ twice a day, and empagliflozin/ linagliptin $-10 \mathrm{mg}+5 \mathrm{mg}, 1$ pill once a day.

Clinical examination revealed body weight of $72 \mathrm{~kg}$, height $1.65 \mathrm{~m}$, BMI $26.4 \mathrm{~kg} / \mathrm{m}^{2}$, tachypnea with a respiratory rate of 26 breaths/minute, drowsiness, a Glasgow Coma Scale of 14 , heart rate of 105 , systolic blood pressure of $100 \mathrm{mmHg}$, diastolic blood pressure of $70 \mathrm{mmHg}$, a mean blood pressure of $80 \mathrm{mmHg}$, and good peripheral perfusion. Due to COVID-19 pandemic scenario, the health workers were wearing their personal protective equipment, including facial masks, which made the evaluation of the presence of acetone smell impracticable.

Chest computed tomography showed ground-glass opacification (Fig. 1). The rapid testing panel for respiratory viruses that included influenza A and $\mathrm{B}$ was negative and the RT-PCR test for SARS-CoV-2 was positive.

On admission, he presented metabolic acidosis with elevated anion gap, arterial pH 7.28, pCO2 $19 \mathrm{mmHg}$, bicarbonate $8.9 \mathrm{mmol} / \mathrm{L}$, and base excess - 15.7. The blood analysis showed creatinine $1.19 \mathrm{mg} / \mathrm{dL}$, blood urea nitrogen (BUN) $14.93 \mathrm{mg} / \mathrm{dL}$, hemoglobin $12 \mathrm{~g} / \mathrm{dL}, 13,300$ leukocytes, 1300 lymphocytes, sodium $132 \mathrm{mEq} / \mathrm{L}$, potassium $5.6 \mathrm{mEq} / \mathrm{L}$, chlorine $99 \mathrm{mEq} / \mathrm{L}, \mathrm{C}$-reactive protein $20.20 \mathrm{mg} / \mathrm{dL}$ (normal value $<0.3 \mathrm{mg} / \mathrm{dL}$ ), glucose $118 \mathrm{mg} /$ $\mathrm{dL}$, and hemoglobin A1c (HbA1c) 7.2\%.

The blood tests were performed after an intravenous hydration therapy with $20 \mathrm{ml} / \mathrm{kg}$ made at the $\mathrm{ED}$, before the patient's transfer to the intensive care unit (ICU).

Given the patient's use of empagliflozin, an oral antidiabetic agent belonging to the SGLT2 inhibitor class, and its association with the risk of eu-DKA [9], we proceeded a ketone bodies investigation with an isolated urine sample, which showed up positive. $\beta$-hydroxybutyric acid level was not available.

At ICU, intravenous regular insulin was started at 4 units per hour $(0.05 \mathrm{UI} / \mathrm{kg} / \mathrm{h})$ with $10 \%$ glucose solution at initial flux of $120 \mathrm{ml} / \mathrm{h}$. Once the patient was not with hyperglycemia, we did not proceed with an administration of an intravenous bolus dose of insulin. The plasma glucose concentration goal was $\sim 11.1-13.9 \mathrm{mmol} / \mathrm{L}$. Potassium levels were monitored every $4 \mathrm{~h}$ and the replacement was made using KCL $19,1 \%$ as needed. The types of fluids and their flow rate were administered based on plasma glucose levels $[5,11]$. The total insulin dose in the first $8 \mathrm{~h}$ was 48 units.

After starting therapy, the patient had a marked recovery in his clinical status, with improvement of electrolyte abnormalities, urinary ketones, and acidosis (Table 1). Concerning the treatment for COVID-19 infection, clinical support measures were performed, which included oxygen therapy using a high-flow nasal cannula for 8 days, with no need
Fig. 1 The patient's chest computed tomography showing ground-glass opacification

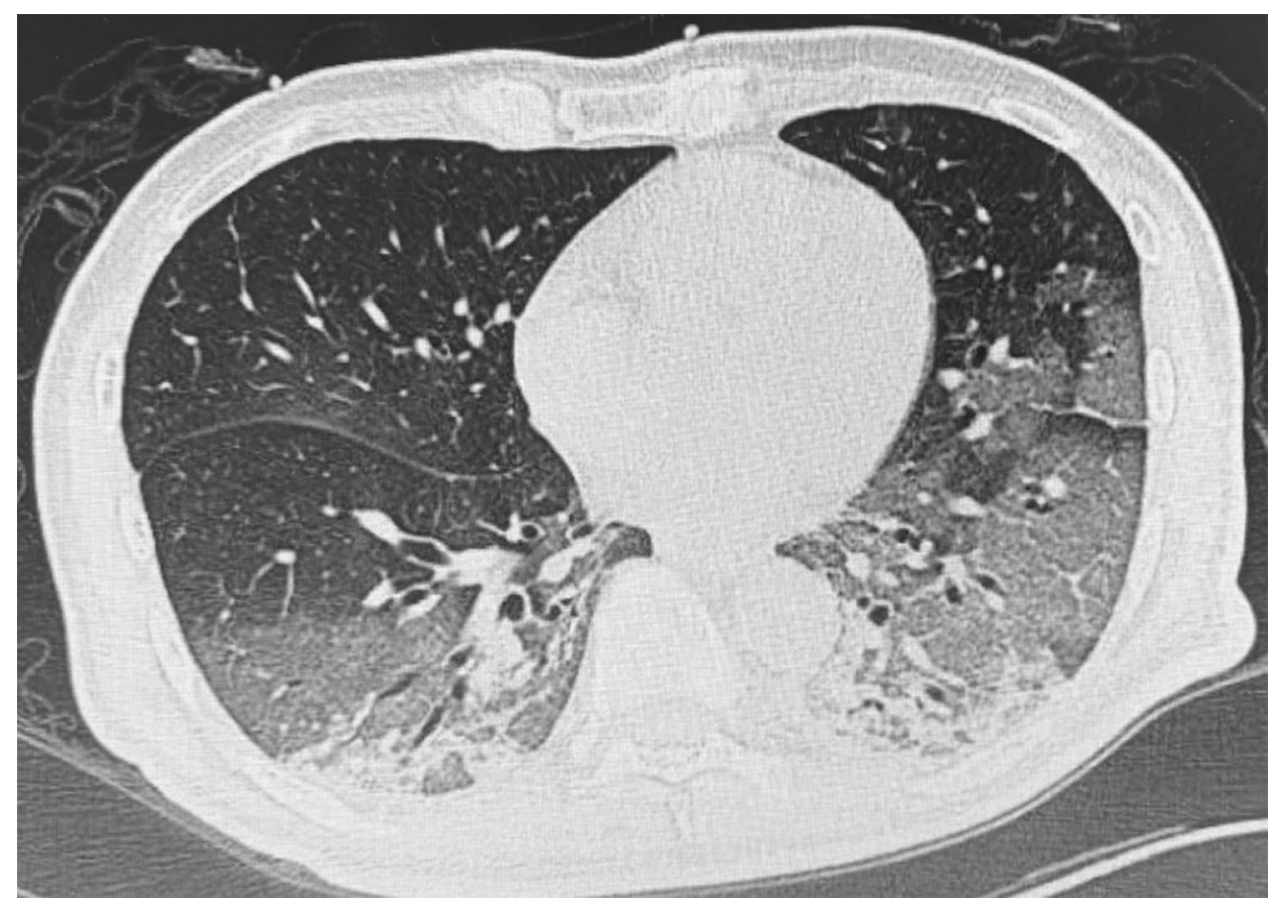


Table 1 Laboratory values from the patient before and after treatment for diabetic ketoacidosis

\begin{tabular}{|c|c|c|}
\hline Blood analyses & $\begin{array}{l}31 / 03 / 2020 \\
22: 12 \\
\text { Before end- } \\
\text { ovenous insulin }\end{array}$ & $\begin{array}{l}01 / 04 / 2020 \\
06: 11 \\
8 \mathrm{~h} \text { after } \\
\text { endovenous } \\
\text { insulin }\end{array}$ \\
\hline $\mathrm{pH}$ & 7.28 & 7.35 \\
\hline $\mathrm{PaO}_{2}(\mathrm{mmHg})$ & 123 & 99 \\
\hline $\mathrm{PCO}_{2}(\mathrm{mmHg})$ & 19 & 34 \\
\hline Sodium bicarbonate $(\mathrm{mmol} / \mathrm{L})$ & 8.9 & 18.8 \\
\hline Base excess (mmol/L) & -15.7 & -6.0 \\
\hline Arterial lactate (mg/dL) & 14 & 12 \\
\hline Sodium (mEq/L) & 132 & 134 \\
\hline Chlorine (mEq/L) & 99 & - \\
\hline Potassium (mEq/L) & 5.6 & 3.1 \\
\hline BUN (mg/dL) & 14.93 & - \\
\hline Uric acid (mg/dL) & 32 & - \\
\hline Creatinine (mg/dL) & 1.12 & 1.19 \\
\hline Glucose (mg/dL) & 118 & 96 \\
\hline $\mathrm{HbA1C}$ & $7.2 \%$ & \\
\hline Urinary Ketones & ++ & + \\
\hline Urinary Glucose & +++ & +++ \\
\hline C-reactive protein $(\mathrm{mg} / \mathrm{dL})$ & 20.20 & - \\
\hline Hemoglobin (g/dL) & 13.5 & 13.9 \\
\hline Leukocytes $(\mu / \mathrm{L})$ & 13,900 & 13,300 \\
\hline Lymphocytes $(\mu / \mathrm{L})$ & 1280 & 1300 \\
\hline Platelets $((\mu / \mathrm{L})$ & 230,000 & 235,000 \\
\hline
\end{tabular}

for invasive mechanical ventilation. In addition, antibiotic therapy with azithromycin $500 \mathrm{mg}$ was administered once a day for the first 5 days of hospitalization, and prophylaxis for venous thromboembolism was carried out with subcutaneous sodium enoxaparin $40 \mathrm{mg}$ once a day during the entire hospitalization. The patient remained in the ICU for 12 days and was discharged after 20 days at hospital, with improvement in his general condition and breathing pattern.

\section{Discussion}

SGLT2 inhibitor drugs are strongly recommended by different societies for the reduction of cardiovascular risk in T2DM patients [12,13], as these drugs reduce the incidence of heart failure and the risk for major cardiovascular events related to atherosclerosis [12]. Therefore, it has become a class of drugs widely used in clinical practice.

COVID-19 infection may increase insulin demand and present gastrointestinal symptoms, such as diarrhea, nausea, and anorexia [14], leading to volume depletion and increased fat breakdown, thus resulting in increased ketone bodies production. This situation can be worsened in susceptible diabetic patients on SLGT2 inhibitors due to the persistent glycosuria which can also cause volume depletion $[15,16]$.

Ketosis and ketoacidosis are complications described in the context of COVID-19. In a study that analyzed 658 patients admitted for COVID-19, 42 had ketosis on admission, of which only 15 were previously diabetic and 3 developed DKA. It is still unclear whether or not there is a higher prevalence of DKA and which mechanism of COVID-19 can induce ketoacidosis [16]. Both DKA and COVID-19 have high levels of inflammatory markers, including IL-6, which have been related to the severity of SARS-CoV-2 infection and with the development of DKA [17].

Eu-DKA is a rare complication in T2DM patients on SGLT2 inhibitors, with a range of $0.16-0.76$ events per 1000 patients-year $[9,18,19]$, but recently some authors recommended that insulin-deficient patients or those using SGLT2 inhibitors should monitor for ketosis using available home testing kits in case of infections.

Mirabelli et al. recommended to withdraw SGLT2 inhibitor in those T2DM patients with severe $\beta$-cell insufficiency who are on insulin therapy at initial symptoms of COVID19 illness [15]. Parlermo et al. and Bornstein et al. had a broader approach and suggested discontinuing SGLT2 inhibitors in the context of COVID-19 infection at the first signs of the illness, regardless of insulin use status, in an attempt to avoid the development of ketoacidosis and acute metabolic decompensation $[17,18]$. Nevertheless, it is described on medical literature that the pharmacological effects of these drugs can persist for several days [20]. Consequently, despite the discontinuation of the drug within the first signs of COVID-19, the patients may still develop eu-DKA and they need to be monitored.

There are two case reports of eu-DKA in the setting of SARS-CoV-2 infection and SGLT2 inhibitor use [17, 21], but we would like to emphasize some differences this report presents. The first difference is that the patient investigated in the present case report has T2DM and developed eu-DKA even without being on previous use of insulin. The second particularity is that the T2DM patient described by Palermo et al. [15] developed eu-DKA after $24 \mathrm{~h}$ of hospitalization, whereas in ours, the patient was already presented to ED with this condition, which reminds us of the importance of evaluating this possibility at the admission of the patient who is using SGLT2 inhibitors.

Once recognized, the management of eu-DKA includes the same triad as the classic DKA: volume resuscitation, potassium and insulin replacement, but with the difference that fluids containing glucose are needed in the initial stage and not later as in the classic DKA [5, 17].

During the actual pandemic scenario, physicians may not initially recognize eu-DKA due to relative euglycemia and delay its treatment. We set out to emphasize the risk of this acute complication in COVID-19-infected patients using 
SGLT2 inhibitors, even if they are not insulin-dependent or have already discontinued the medication. The medical community should keep in mind the possibility that a SARSCoV-2-infected patient with a high anion gap metabolic acidosis and that is using that drug class can be undergoing eu-DKA, so physicians can provide this patient with appropriated treatment.

All procedures conducted herein were in accordance with the ethical standards of the institutional and national committees on human experimentation, as well as with the 1964 Helsinki Declaration and later versions. Informed consent or a substitute thereof was obtained from the patient included in this study.

Acknowledgements We received no funding for preparation of this article.

\section{Compliance with ethical standards}

Conflict of interest The authors have no conflicts of interests to disclose.

\section{References}

1. Pinto LC, Bertoluci MC. Type 2 diabetes as a major risk factor for COVID-19 severity: a meta-analysis. Arch Endocrinol Metab. 2020;64(3):199-200. https://doi.org/10.20945/2359-3997000000 256

2. Xu Z, Wang Z, Wang S, et al. The impact of type 2 diabetes and its management on the prognosis of patients with severe COVID-19. J Diabetes. 2020. https://doi.org/10.1111/1753-0407.13084.

3. Zhu L, She Z-G, Cheng X, Guo J, Zhang B-H, Correspondence HL. Clinical and translational report association of blood glucose control and outcomes in patients with COVID-19 and pre-existing type 2 diabetes. Cell Metab. 2020;31(1068-1077):e3. https://doi. org/10.1016/j.cmet.2020.04.021.

4. Yasuda K, Tanahashi H, Hayashi M, Yamakita N. Hyperglycemic crises in adult patients with diabetes: response to Kitabchi et al. Diabetes Care. 2009;32(12):e157-e157. https://doi.org/10.2337/ dc09-1431.

5. Barski L, Eshkoli T, Brandstaetter E, Jotkowitz A. Euglycemic diabetic ketoacidosis. Eur J Intern Med. 2019;63:9-14. https:// doi.org/10.1016/j.ejim.2019.03.014.

6. U.S. Food and Drug Administration. Drug Safety Communication: FDA warns that SGLT2 inhibitors for diabetes may result in a serious condition of too much acid in the blood [Internet]. 2015. https://www.fda.gov/downloads/drugs/drugsafety/ucm44 6954.pdf. Accessed 15 July 2020.

7. Peters AL, Buschur EO, Buse JB, Cohan P, Diner JC, Hirsch IB. Euglycemic diabetic ketoacidosis: a potential complication of treatment with sodium-glucose cotransporter 2 inhibition. Diabetes Care. 2015;38(9):1687-93. https://doi.org/10.2337/dc15-0843.

8. Meyer EJ, Gabb G, Jesudason D. SGLT2 inhibitor-associated euglycemic diabetic ketoacidosis: a south australian clinical case series and australian spontaneous adverse event notifications.
Diabetes Care. 2018;41(4):e47-9. https://doi.org/10.2337/ dc17-1721.

9. Tang H, Li D, Wang T, Zhai S, Song Y. Effect of sodium-glucose cotransporter 2 inhibitors on diabetic ketoacidosis among patients with type 2 diabetes: a meta-analysis of randomized controlled trials. Diabetes Care. 2016;39(8):e123-4. https://doi.org/10.2337/ dc16-0885.

10. Ogawa W, Sakaguchi K. Euglycemic diabetic ketoacidosis induced by SGLT2 inhibitors: possible mechanism and contributing factors. J Diabetes Investig. 2016;7(2):135-8. https://doi. org/10.1111/jdi.12401.

11. Kitabchi AE, Umpierrez GE, Miles JM, Fisher JN. Hyperglycemic crises in adult patients with diabetes. Diabetes Care. 2009;32(7):1335-43. https://doi.org/10.2337/dc09-9032.

12. Scheen AJ. Challenging 2019 ESC guidelines for the management of type 2 diabetes. Diabetes Metab. 2020;46(3):181-5. https://doi. org/10.1016/j.diabet.2019.10.006.

13. American Diabetes Association. 10. Cardiovascular disease and risk management: standards of medical care in diabetes-2020. Diabetes Care. 2020;43(Suppl 1):S111-34. https://doi.org/10.2337/ dc20-S010.

14. Mao R, Qiu Y, He JS, et al. Manifestations and prognosis of gastrointestinal and liver involvement in patients with COVID19: a systematic review and meta-analysis. Lancet Gastroenterol Hepatol. 2020;5(7):667-78. https://doi.org/10.1016/S2468 -1253(20)30126-6.

15. Mirabelli M, Chiefari E, Puccio L, Foti DP, Brunetti A. Potential benefits and harms of novel antidiabetic drugs during COVID-19 crisis. Int J Environ Res Public Health. 2020;17(10):3664. https ://doi.org/10.3390/ijerph17103664.

16. Li J, Wang X, Chen J, Zuo X, Zhang H, Deng A. COVID-19 infection may cause ketosis and ketoacidosis. Diabetes Obes Metab. 2020. https://doi.org/10.1111/dom.14057.

17. Palermo NE, Sadhu AR, McDonnell ME. Diabetic ketoacidosis in COVID-19: unique concerns and considerations. J Clin Endocrinol Metab. 2020;105(8):2819. https://doi.org/10.1210/clinem/ dgaa360.

18. Bornstein SR, Rubino F, Khunti K, et al. Practical recommendations for the management of diabetes in patients with COVID19. Lancet Diabetes Endocrinol. 2020;8(6):546-50. https://doi. org/10.1016/S2213-8587(20)30152-2.

19. Garber AJ, Handelsman Y, Grunberger G, et al. Consensus statement by the american association of clinical endocrinologists and american college of endocrinology on the comprehensive type 2 diabetes management algorithm-2020 executive summary. Endocr Pract. 2020;26(1):107-39. https://doi.org/10.4158/CS-2019-0472.

20. Handelsman Y, Henry RR, Bloomgarden ZT, et al. American Association Of Clinical Endocrinologists And American College Of Endocrinology position statement on the association of SGLT-2 inhibitors and diabetic ketoacidosis. Endocr Pract. 2016;22(6):753-62. https://doi.org/10.4158/EP161292.PS.

21. Oriot P, Hermans MP. Euglycemic diabetic ketoacidosis in a patient with type 1 diabetes and SARS-CoV-2 pneumonia: case report and review of the literature. Acta Clin Belg. 2020. https:// doi.org/10.1080/17843286.2020.1780390.

Publisher's Note Springer Nature remains neutral with regard to jurisdictional claims in published maps and institutional affiliations. 